\title{
SOLITARY CILIA IN ENDOMETRIAL FIBROBLASTS
}

\author{
L. E. MARASPIN AND A. V. BOCCABELLA
}

Departments of Anatomy, The Medical College of Wisconsin (formerly Marquette School of Medicine), Milwaukee, Wisconsin, and New Jersey College of Medicine and Dentistry, Newark, New Fersey, U.S.A.

(Received 12th Fuly 1970)

\begin{abstract}
Summary. This paper reports the presence of solitary cilia in endometrial fibroblasts and presents evidence indicating that ciliogenesis in the rat endometrium may be hormonally controlled. Very few solitary cilia are present in endometrial fibroblasts during oestrus and after the administration of oestradiol. Solitary cilia in endometrial fibroblasts are most numerous during the quiescent phases of the oestrous cycle. Ovariectomy, ovariectomy-hypophysectomy and progesterone treatment do not alter the occurrence of this organelle in endometrial fibroblasts.
\end{abstract}

\section{INTRODUCTION}

This paper reports the presence of cilia in rat endometrial fibroblasts and describes the process of ciliogenesis during both the normal oestrous cycle and under several experimental conditions.

\section{MATERIAL AND METHODS}

Normally cycling animals

Vaginal smears were taken from young virgin female rats of the Wistar strain during three consecutive oestrous cycles of 4 to 5 days each to establish the presence of normal ovarian activity. Those animals which were considered normal were permitted to enter the fourth cycle and then were killed during the various stages of the oestrous cycle, when vaginal smears and gross observations of the uterus and ovaries confirmed the stage of the oestrous cycle. At least seven animals were studied in each of the four phases.

Hypophysectomized, ovariectomized, hormone-treated animals

Rats used in these studies were also followed through three consecutive oestrous cycles to establish the presence of normal ovarian activity. Bilateral ovariectomy was then performed through an abdominal incision, the animals subsequently being allowed to recover for 14 days. During this time, the vaginal smears were continued in order to confirm the completeness of the ovariectomy. Hypophysectomized rats were obtained from Hormone Assay Laboratories and were then ovariectomized and followed as described above. 
Three experimental groups were established: (1) ovariectomized animals receiving (a) $2.0 \mu \mathrm{g}$ of oestradiol-17 $\beta$, (b) $1.0 \mathrm{mg}$ progesterone, (c) oestradiol and progesterone, and (d) almond oil vehicle; (2) hypophysectomizedovariectomized animals treated as in (1); and (3) ovariectomized animals receiving $0.02,0.20,2.0$ or $20 \mu \mathrm{g}$ of oestradiol. The hormones were dissolved in $0.2 \mathrm{ml}$ of almond oil and were injected subcutaneously for 3 days. The animals were killed $24 \mathrm{hr}$ after the last injection and the uteri were removed and prepared for electron microscopy.

Several segments of uteri were cut into small pieces and immediately fixed in $1.0 \%$ osmium tetroxide in a phosphate buffer containing $5 \%$ glucose at $4{ }^{\circ} \mathrm{C}$ and at a pH of 7.2 to 2 for $3 \mathrm{hr}$ according to the methods of Millonig (1961). Specimens were embedded in DER 332 according to Lockwood (1964). Thin sections were prepared with a Porter-Blum ultramicrotome and were stained by the lead hydroxide method of Karnovsky (1961) or by the double stain method of Reynolds (1963) and viewed in a Phillips 100-B or RCA-EMU 4 electron microscope.

\section{OBSERVATIONS}

Solitary cilia were observed in the cytoplasm of endometrial fibroblasts during all phases of the oestrous cycle but were seen more frequently during dioestrus and metoestrus than during pro-oestrus or oestrus (Pl. 1. Fig. 1).

In comparison with dioestrous animals (controls), neither ovariectomy alone,

\section{EXPLANATION OF PLATE 1}

Fic. 1. Endometrial fibroblast from a dioestrous rat showing an emergent solitary cilium extending into the extracellular $\left(^{*}\right)$ space. Diplosome $\left(\mathrm{C}_{1} \mathrm{C}_{2}\right)$. One of the diplosomal centrioles $\left(\mathrm{C}_{2}\right)$ shows a cilium $(\uparrow)$. Nucleus $(\mathrm{N}) . \times 22,870$.

Fic. 2. Endometrial fibroblast from a hypophysectomized-ovariectomized, untreated rat, showing a solitary cilium (C). Nucleus (N); Golgi complex (G). Note the ciliary sheath is continuous with the cell membrane $(\uparrow) . \times 15,900$.

Frg. 3. Diplosome $\left(\mathrm{G}_{1} \mathrm{G}_{2}\right)$, near the cell nucleus. One of the diplosomal centrioles $\left(\mathrm{G}_{1}\right)$ will give rise to a cilium. $\times 56,300$.

Fig. 4. An oblique section through the centriole-basal body complex $\left(G_{1}\right)$. Several satellites (s) are attached to the main cylindrical structure. $\times 70,582$.

Fig. 5. Cross-section of the centriole-basal body complex $\left(\mathrm{C}_{1}\right)$. Several satellites with knob-like endings $\left(^{*}\right)$ extend from the cylindrical structure. Golgi complex $(G)$. $\times 47,054$.

Fig. 6. An oblique section through two rootlet filaments $\left(\uparrow_{1} \uparrow_{2}\right)$ of the centriole-basal body complex. Golgi complex (G). × 31,370.

FIG. 7. The centriole-basal body complex $\left(\mathrm{C}_{1}\right)$ is cut in a mid-sagittal plane showing the forming ciliary bud $(C)$ surrounded by the periciliary vesicle $(\uparrow)$. Golgi complex $(G)$; rootlet filament $(F) . \times 63,439$.

Fig. 8. A developing cilium from the cilium-forming centriole $\left(\mathrm{G}_{1}\right)$ appears to invaginate the periciliary vesicle $(\uparrow)$. Golgi complex $(G)$; non-ciliary centriole $\left(\mathrm{C}_{2}\right) . \times 36,800$.

Fic. 9. A developing cilium surrounded by its sheath $(\uparrow)$. The centriole-basal body complex $\left(C_{1}\right)$ shows satellites $(s)$ and rootlet filaments $(F)$ attached to its periphery. $\times 27,405$.

Fic. 10. A cross-section through the cilium (C). The cilium is surrounded by a ciliary sheath (CS). It contains nine doublet fibres (DF) and lacks a central pair. $\times 58,000$. 
PI.ATE 1
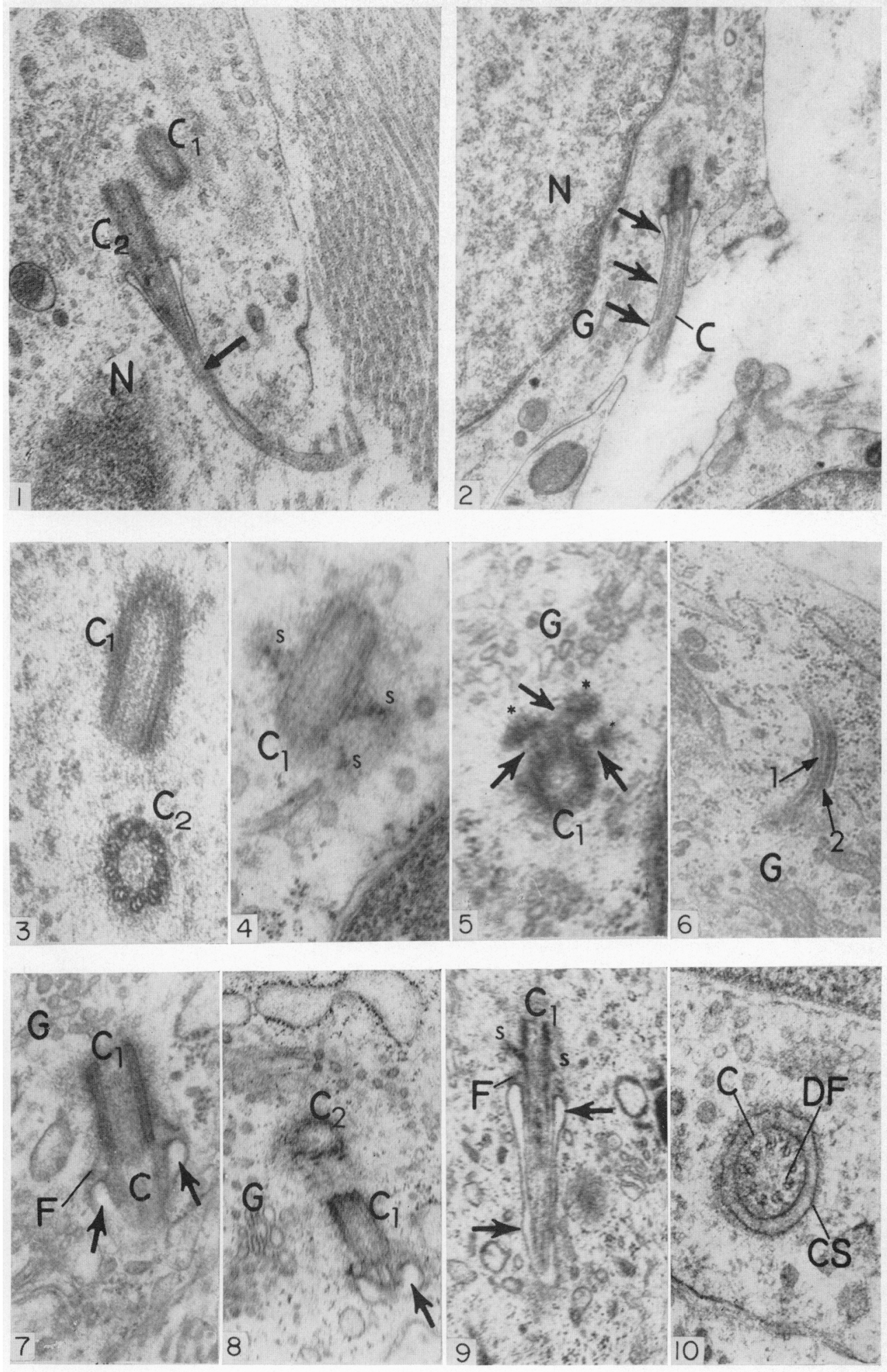
nor hypophysectomy-ovariectomy altered the ciliary morphology or the frequency of endometrial fibroblasts (Pl. 1, Fig. 2). Progesterone administered for 3 days to these experimental animals had no effect on ciliary morphology or frequency.

In contrast to the effect of progesterone, oestradiol in doses of $0.20 \mu \mathrm{g}, 2.0 \mu \mathrm{g}$ and $20 \mu \mathrm{g}$ induced progressive reductions in the occurrence of solitary cilia. Rarely was a solitary cilium observed in the cytoplasm of an endometrial fibroblast from an animal treated with $2.0 \mu \mathrm{g}$ or $20 \mu \mathrm{g}$. When oestradiol was administered concurrently with progesterone, endometrial cilia were as rare as when the animals were treated with oestradiol alone. The effects of these hormones in hypophysectomized-ovariectomized animals were the same as those in ovariectomized ones.

The process of ciliogenesis was similar in all fibroblasts observed. One centriole of the diplosome differentiated to form the basal body of the future cilium (PI. 1, Figs. 1, 3). Usually this centriole-basal body complex had one to three satellites extending from its cut surface which ended distally as small 'knobs' orientated perpendicularly to the longitudinal axis (Pl. 1, Figs. 4, 5). In addition, banded rootlet filaments extended from the basal body and radiated into the cytoplasm (P1. 1, Figs. 6, 7, 9). These filaments were about $200 \AA$ thick and were cross-striated with a periodicity of approximately $600 \AA$. The other centriole lacked such elements.

The first indication of the formation of a cilium was the occurrence of a pericentriolar basal body vesicle (Pl. I, Fig. 7) at the most distal end of the centriole-basal body complex. The vesicle is believed to be an extension of the cell membrane since in longitudinal section this vesicle is continuous with the cell membrane (Pl. 1, Figs. 1, 2).

Originating from the distal end of the centriole-basal body complex is a ciliary bud (Pl. 1, Fig. 8). It is assumed that, as the ciliary bud grows, the cell membrane progressively invaginates along the developing bud. The latter forms a double membranous sac or sheath around the growing cilium (Pl. 1, Fig. 9).

The cilium develops by elongation and the ciliary sheath lengthens concurrently with the ciliary shaft.

\section{DISCUSSION}

The general appearance of solitary cilia in endometrial fibroblasts reported in this study appears to be similar to those described in the $\beta$-cells of the mouse pancreatic islets (Munger, 1958); to those of the mouse adenohypophysis described by Barnes (1961) and to similar organelles described by Wheatley $(1967,1969)$ in the adrenal cortex and pars distalis of the adenohypophysis. Apart from endocrine tissue, solitary cilia in typical endometrial fibroblasts as described in this report are also similar to the detailed description of this organelle in rat endometrial tissue made by Tachi, Tachi \& Lindner (1969), though these authors studied endometrial decidual cells rather than typical endometrial fibroblasts. Furthermore, solitary cilia in endometrial fibroblasts are also similar to those observed in the granular neurons of the cerebral 
cortex (Dahl, 1963), in retinal pigment epithelium (Allen, 1965), and in embryonic tissues and organ cultures (Sorokin, 1962).

Although the present study confirms some observations made by other investigators, it also indicates that solitary cilia in many different tissues and locations are, in general, structuraily similar. This paper reports the presence of solitary cilia in endometrial fibroblasts and in reference to this cell type suggests that ciliogenesis in the rat endometrium may be hormonally controlled by the fact that the incidence of this organelle in endometrial fibroblasts appears to vary according to the uterine endocrine physiology. The presence of satellites on the centriole-basal body complex is not new, but to find multiple satellites as shown in this report appears to be a rarity. The function of these satellites, apart from mechanical support, is open to conjecture. Endometrial fibroblasts containing solitary cilia also have banded rootlet filaments emanating from the basal body. As in other tissues, solitary cilia in endometrial fibroblasts do not possess the typical pair of filaments in the axoneme (Pl. 1, Fig. 10). The finding would suggest a different function for this organelle than that of the typical 'nine + two' type of cilia.

Since all cells contain centrioles, the frequency of cilia in endometrial fibroblasts could be related to the number of centrioles found. Since random sectioning of fibroblasts will only result in the observation of the centrioles and the cilium of a cell when they have been cut in the same plane, the finding of ciliary processes in every fourth or fifth centriolar complex indicates that the percentage of endometrial fibroblasts with cilia is probably very high.

The exact function of solitary cilia remains unknown. Sorokin (1962) pointed out that ciliogenesis is frequently observed in those mesodermal derivatives undergoing active differentiation, e.g. in fibroblasts actively forming collagen. It should be noted that other authors (Munger, 1958; Barnes, 1961; Wheatley, 1967) have also attributed sensory or chemoreceptor functions to the solitary cilia of several different tissues and animal species. If these suggested functions do, in fact, apply, then this organelle may control the secretory and other functions of the endometrial fibroblasts.

It is suggested from the present electron microscopic analysis of solitary cilia in endometrial fibroblasts that this organelle may also be responsive to endogenous and exogenous ovarian hormones. This hypothesis is substantiated by the varying occurrence of solitary cilia in endometrial fibroblasts during the normal oestrous cycle: very few solitary cilia are present in endometrial fibroblasts during oestrus, a period of heightened oestrogen secretion by the animal. A similar suppression is observed during exogenous oestrogen treatment, suggesting that a high oestrogen titre in a female rat has an inhibitory effect on ciliogenesis in endometrial fibroblasts. Although Tachi et al. (1969) made no attempt to establish whether there is any significant quantitative difference in the incidence of cilia at different stages, they reported that such cilia are encountered most frequently in stromal cells during the postimplantation stages. It is recognized that during this time, the endometrium of a rat is controlled by many hormonal metabolites, some of which act synergistically. The apparent inhibitory effect on solitary cilia by oestrogen observed in this study may, therefore, be masked or altogether absent. 


\section{REFERENCES}

Allen, R. A. (1965) Isolated cilia in inner retinal neurons and in retinal pigment epithelium. $\mathcal{F}$. Ultrastruct. Res. 12, 730.

BARNes, G. B. (1961) Ciliated secretory cells in the pars distalis of the mouse hypophysis. f. Ultrastruct. Res. 5, 453.

DAHL, H. A. (1963) Fine structure of cilia in rat cerebral cortex. Z. Zellforsch. mikrosk. Anat. 60, 369.

KARNovsky, M. J. (1961) Simple methods for "staining with lead" at high pH in electron microscopy. 7. biophys. biochem. Cytol. 11, 729.

Lockwood, W. R. (1964) A reliable and easily sectioned epoxy embedding medium. Anat. Rec. 159, 129.

MrLlonic, G. (1961) A modified procedure for lead staining of thin sections. F. biophys. biochem. Cytol. $11,736$.

MuNGer, B. L. (1958) A light and electron microscopic study of cellular differentiation in the pancreatic islets of the mouse. Am. F. Anat. 103, 275.

RRYNOLDs, E. S. (1963) The use of lead citrate at high pH as an electron opaque stain in electron microscopy. 7. Cell Biol. 17, 208.

Soroxin, S. (1962) Centrioles and the formation of rudimentary cilia by fibroblasts and smooth muscle cells. F. Cell Biol. 15, 363 .

TACH, S., TACHI, G. \& LiNDNER, H. R. (1969) Cilia-bearing stromal cells in the rat uterus. F. Anat. 104, 295.

Wheatrey, D. N. (1967) Cilia and centrioles of the rat adrenal cortex. F. Anat. 101, 223.

WheAtLey, D. N. (1969) Cilia in cell-cultured fibroblasts. F. Anat. 105, 351. 